\title{
Evaluasi Mutu Beton Menggunakan Beton Inti Diameter Kecil
}

\author{
Yulius Rakhman*1, Herman Parung ${ }^{1}$, Rita Irmawaty ${ }^{1}$ \\ ${ }^{1}$ Departemen Teknik Sipil, Fakultas Teknik, Universitas Hasanuddin, Makassar \\ Jl. Poros Malino km. 6, Bontomarannu, Kabupaten Gowa, Sulawesi Selatan 92171 \\ *Email: yuliussurabaya@gmail.com
}

DOI: 10.25042/jpe.052019.10

\begin{abstract}
Abstrak
Salah satu penyebab keterbatasan pengambilan sampel beton inti karena keberadaan tulangan pada struktur beton. Jika digunakan diameter core besar, dapat menurunkan kapasitas struktur beton dengan adanya tulangan yang terpotong. Oleh karena itu, dilakukan studi penggunaan core beton diameter kecil untuk memprediksi kuat tekan beton diameter kecil terhadap silinder beton diameter standar. Benda uji berupa (a) silinder beton berdiameter $10 \mathrm{~cm}$ dan tinggi $20 \mathrm{~cm}$; (b) 2 plat beton berdimensi $45 \mathrm{~cm}$ x $45 \mathrm{~cm}$ x $13 \mathrm{~cm}$; dan (c) 4 balok beton berdimensi $70 \mathrm{~cm}$ x $30 \mathrm{~cm} \times 15 \mathrm{~cm}$. Metode pengambilan sampel core diameter 2 inchi dan 1 inchi dengan arah sejajar dan tegak lurus arah pengecoran. Ada 2 variasi mutu beton yaitu $20 \mathrm{MPa}$ dan $30 \mathrm{Mpa}$ dengan MSA masing-masing $10 \mathrm{~mm}$ dan $20 \mathrm{~mm}$. Pengujian kuat tekan dan modulus elastisitas beton dilakukan, serta uji normalitas beton inti untuk mengevaluasi kecukupan benda uji. Dari hasil pengujian dapat disimpulkan bahwa kuat tekan beton inti 2 inchi dengan pengambilan benda uji sejajar dan tegak lurus arah pengecoran memenuhi syarat uji normalitas, sehingga dapat direkomendasikan dengan jumlah sampel 25 buah, sedangkan untuk sampel berdiameter 1 inchi jumlah sampelnya perlu ditambah.
\end{abstract}

\begin{abstract}
Correlation of Concrete by Using Small Core Diameter. One of the causes of limited sampling on concrete structures is that there are reinforcement in the concrete structure, so that when using a large diameter drill core, can damage the concrete structure. Therefore a study of small diameter concrete was conducted to predict the compressive strength of cylindrical concrete. Test specimens in the form of concrete cylinders with dimension $10 \mathrm{~cm}$ x $20 \mathrm{~cm}, 2$ concrete plates with dimension $45 \mathrm{~cm} \times 45 \mathrm{~cm} \times 13 \mathrm{~cm}$ and 4 concrete beams with dimensions $70 \mathrm{~cm}$ x $30 \mathrm{~cm}$ x $15 \mathrm{~cm}$ by taking concrete using a drill core diameter of 2" and 1". Two concrete slabs and two concrete beams with concrete strength (f'c) 20 MPa (MSA 20mm and $10 \mathrm{~mm}$ ) while two concrete concrete slabs and two concrete beams with concrete strength (f'c) 30 MPA (MSA 20mm and $10 \mathrm{~mm})$. Types of tests carried out include testing the compressive strength of concrete, core concrete normality test, modulus of elasticity and compressive strength of the core concrete. From test results, can be concluded that the compressive strength of core concrete with sample in the direction of casting for a diameter of 2 inches and concrete strength of $20 \mathrm{MPa}$ (MSA $20 \mathrm{~mm}$ and $10 \mathrm{~mm}$ ) meets the requirements and can be recommended with number samples of 25, whereas for diameter 1 " the number of samples must be added.
\end{abstract}

Kata Kunci: Beton inti, core drill, kuat tekan

\section{Pendahuluan}

Beton menurut ASTM C125-06a [1] "Standard Terminology Relating to Concrete and Concrete Aggregates" didefinisikan sebagai bahan komposit dengan penyusun utamanya berupa partikel atau fragmen berbentuk agregat yang saling mengikat dan melekat. Kualitas beton dipengaruhi oleh banyak hal, diantaranya oleh material penyusunnya, komposisi campuran, cara pengerjaan, dan perawatan. ASTM C42-16 "Standard Test Method for Obtaining and Testing Drilled Core and Sawed Beams of Concrete" [2] menetapkan ukuran standar sampel beton inti yaitu berdiameter minimum 4 inci $(100 \mathrm{~mm})$.

Pada kenyataannya beton inti dengan diameter lebih kecil sering digunakan karena lebih mudah dalam pengerjaan, perawatan, dan penyimpanan, serta lebih cepat dibandingkan dengan ukuran standar. Beton inti berdiamater kecil juga lebih meminimalkan kerusakan struktur seperti tidak memotong tulangan yang ada pada suatu struktur dengan tulangan yang rapat dan menghasilkan lubang yang lebih kecil untuk dilakukan perbaikan. Permasalahan yang muncul kemudian adalah nilai kuat tekan dari beton inti berdiameter 
kecil mempunyai nilai koefisien variasi yang besar sehingga agak sulit untuk menentukan nilai kuat tekan yang sebenarnya.

Berdasarkan penelitian yang dilakukan oleh Yamamoto, dkk [3] penggunaan spesimen beton inti berdiameter kecil pada uji kuat tekan elemen struktur merupakan teknologi yang memberikan sedikit kerusakan pada struktur saat pengambilan sampel dilakukan. Namun, variasi hasil uji kuat tekan beton inti berdiameter kecil menjadi besar dan sulit untuk mengevaluasi secara tepat nilai kekuatan tekannya dan berdasarkan penelitian yang dilakukan oleh Yamamoto, dkk [4], kekuatan tekan inti berdiameter kecil cenderung lebih besar jika kadar volume agregat kasar dari spesimen lebih tinggi.

\section{Bahan dan Metode}

\subsection{Lokasi Penelitian}

Pengambilan dan Pembuatan Sampel menggunakan Core Drilled Test ini dilakukan di Laboratorium Struktur dan Bahan departemen Teknik Sipil Universitas Hasanuddin.

\subsection{Desain Penelitian}

Benda uji yang dibuat di Laboratorium Struktur dan Bahan Departemen Teknik Sipil, Fakultas Teknik, Universitas Hasanuddin adalah berbentuk plat ukuran 450 x 450 x $130 \mathrm{~mm}$, balok ukuran 700 x 300 x $150 \mathrm{~mm}$ dan silinder ukuran 200 x $100 \mathrm{~mm}$ dengan 2 (dua) mutu yang berbeda (f'c $20 \mathrm{Mpa}$ dan f'c $30 \mathrm{Mpa}$ ) dan 2 (dua) agregat kasar dengan MSA yang berbeda (MSA $10 \mathrm{~mm}$ dan MSA $20 \mathrm{~mm}$ ). Gambar 1 menunjukan desain benda uji.

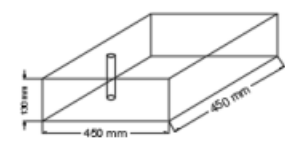

Sample Plat $450 \times 450 \times 130 \mathrm{~mm}$

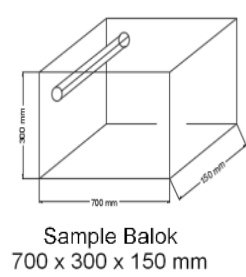

$700 \times 300 \times 150 \mathrm{~mm}$

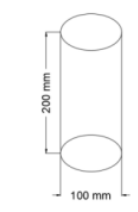

Sample Silinder $200 \times 100 \mathrm{~mm}$
Gambar 1. Desain benda uji

\subsection{Metode Pengumpulan Data}

Pengumpulan data dibantu oleh teman-teman mahasiswa S1 di Laboratorium Struktur dan Bahan departemen Teknik Sipil Universitas Hasanuddin. Data yang diambil di Laboratorium Struktur dan Bahan Departemen Teknik Sipil, Fakultas Teknik, Universitas Hasanuddin adalah data dari hasil core drill $\varnothing 2$ inci, $\varnothing 1$ inci dengan metode pengambilan arah sejajar (plat beton) dan tegak lurus pengecoran (balok beton) serta beton silinder dengan cara pengujian kuat tekan, pengujian uji normalitas sampel beton inti, pengujian modulus elastisitas, dan evaluasi kuat tekan beton inti yaitu mencari faktor korelasi antara beton inti dengan beton silinder. Sampel yang diambil di laboratorium terbagi jadi 4 variasi yaitu variasi A (f'c $20 \mathrm{MPa}$ dan MSA $20 \mathrm{~mm}$ ), Variasi B (f'c $20 \mathrm{MPa}$ dan MSA $10 \mathrm{~mm}$ ), Variasi C (f'c $30 \mathrm{MPa}$ dan MSA $20 \mathrm{~mm}$ ), Variasi D (f'c $30 \mathrm{MPa}$ dan MSA $10 \mathrm{~mm}$ ).

\section{Hasil Penelitian}

\subsection{Pengujian Kuat Tekan}

Kuat tekan beton dipengaruhi oleh faktor air semen, sifat dan jenis agregat, jenis campuran, kelecakan (workability), perawatan (curing) beton dan umur beton [5-7]. Kuat tekan benda uji beton inti dihitung dengan menggunakan rumus :

$$
f^{\prime} c=\frac{P}{A}
$$

dimana:

$f^{\prime} c=$ kuat tekan $(\mathrm{MPa})$

$\mathrm{P} \quad=$ beban uji maksimum yang ditunjukkan oleh mesin uji tekan $(\mathrm{N})$.

A = luas penampang benda uji $\left(\mathrm{mm}^{2}\right)$.

Dari hasil rata-rata test nilai kuat tekan dari beton silinder usia 28 hari dengan nilai ditiap variasi adalah sebagai berikut variasi A 21,25 $\mathrm{MPa}$, variasi B 24,27 $\mathrm{MPa}$, variasi C 33,82 $\mathrm{MPa}$, variasi D 34,67 MPa.

Tabel 1 menunjukkan hasil kuat tekan dari beton inti pengambilan sampel sejajar arah pengecoran dengan diameter 2 inci dan 1 inci adalah sebagai berikut untuk diameter 2 inci variasi A 22,18 MPa, variasi B 26,98 $\mathrm{MPa}$, variasi 
C 31,70 $\mathrm{MPa}$, variasi D 33,06 $\mathrm{MPa}$ sedangkan untuk diameter 1 inci variasi A 20,06 $\mathrm{MPa}$, variasi B 24,00 $\mathrm{MPa}$, variasi C 27,15 $\mathrm{MPa}$, variasi $\mathrm{D}$ 28,61 MPa dan hasil kuat tekan dari beton inti pengambilan sampel tegak lurus arah pengecoran dengan diameter 2 inci dan 1 inci adalah sebagai berikut untuk diameter 2 inci variasi A 20,44 $\mathrm{MPa}$, variasi B 26,27 MPa, variasi C 29,25 $\mathrm{MPa}$, variasi D 30,36 MPa sedangkan untuk diameter 1 inci variasi A 17,94 $\mathrm{MPa}$, variasi B 23,94 $\mathrm{MPa}$, variasi C 24,92 $\mathrm{MPa}$, variasi D 27,70 $\mathrm{MPa}$.

Tabel 1. Nilai kuat tekan beton inti dan beton silinder

\begin{tabular}{cccccc}
\hline & & \multicolumn{3}{c}{ Beton Inti (Mpa) } \\
\cline { 3 - 6 } Sampel & $\begin{array}{c}\text { Beton } \\
\text { Silinder } \\
\text { (Mpa) }\end{array}$ & $\begin{array}{c}\text { Pengambilan } \\
\text { sejajar arah } \\
\text { pengecoran }\end{array}$ & \multicolumn{2}{c}{$\begin{array}{c}\text { Pengambilan } \\
\text { Tegak Lurus } \\
\text { Arah Pengecoran }\end{array}$} \\
\cline { 3 - 6 } & & $\begin{array}{c}\boldsymbol{\emptyset ~ 2} \\
\text { inci }\end{array}$ & $\begin{array}{c}\boldsymbol{\emptyset ~ 1 ~} \\
\text { inci }\end{array}$ & $\begin{array}{c}\text { Ø 2 } \\
\text { inci }\end{array}$ & $\begin{array}{c}\text { Ø 1 } \\
\text { inci }\end{array}$ \\
\hline A & 21.25 & 22.18 & 20.06 & 20.44 & 17.94 \\
B & 24.27 & 26.98 & 24.00 & 26.27 & 23.94 \\
C & 33.82 & 31.70 & 27.15 & 29.25 & 24.92 \\
D & 34.67 & 33.06 & 28.61 & 30.36 & 27.70 \\
\hline
\end{tabular}

\subsection{Pengujian Normalitas Beton Inti}

Tabel 2 menunjukkan hasil pengujian normalitas beton inti dapat dilihat apakah dapat mencukupi atau tidak jumlah pengujian sebanyak 25 sampel disetiap variasi untuk menentukan nilai kuat tekan.

Tabel 2. Pengujian normalitas beton inti

\begin{tabular}{|c|c|c|c|c|}
\hline \multirow{3}{*}{ Sampel } & \multicolumn{4}{|c|}{ Beton Inti (Mpa) } \\
\hline & \multicolumn{2}{|c|}{$\begin{array}{c}\text { Pengambilan Sejajar } \\
\text { Arah Pengecoran }\end{array}$} & \multicolumn{2}{|c|}{$\begin{array}{c}\text { Pengambilan Tegak } \\
\text { Lurus Arah } \\
\text { Pengecoran } \\
\end{array}$} \\
\hline & Ø 2 inci & $\varnothing 1$ inci & Ø 2 inci & Ø 1 inci \\
\hline A & $\sqrt{ }$ & $\sqrt{ }$ & $\sqrt{ }$ & $\mathrm{x}$ \\
\hline B & $\sqrt{ }$ & $\mathrm{x}$ & $\mathrm{x}$ & $\mathrm{x}$ \\
\hline $\mathrm{C}$ & $\sqrt{ }$ & $\sqrt{ }$ & $\mathrm{x}$ & $\mathrm{x}$ \\
\hline $\mathrm{D}$ & $\sqrt{ }$ & $\mathrm{x}$ & $\sqrt{ }$ & $\mathrm{x}$ \\
\hline
\end{tabular}

\subsection{Pengujian Modulus Elastisitas}

Modulus elastistas beton menurut ASTM C469-02 adalah nilai tegangan regangan beton dalam kondisi elastis, pada saat tegangan menjadi $40 \%$ dari kuat tekan tekan maksimum. Pengujian modulus elastisitas ini bertujuan untuk menentukan mutu beton yang disyaratkan modulus elastisitas dari sampel beton pada umur 28 hari. Rumus modulus elastisitas secara eksperimental dihitung dengan rumus:

$$
E_{C}=\frac{S_{2}-S_{1}}{\varepsilon_{2}-0,0005}
$$

dimana:

$$
\begin{aligned}
& \mathrm{E}_{\mathrm{C}}=\text { Modulus elastisitas beton }(\mathrm{MPa}) \\
& \mathrm{S}_{1}=\text { Tegangan pada saat regangan } \\
& \text { longitudinal } \varepsilon_{1}=0,00005(\mathrm{MPa}) \\
& \mathrm{S}_{2}=\text { Tegangan pada saat } 40 \% \text { beban } \\
& \text { maksimum (MPa) } \\
& \varepsilon_{2}=\text { Regangan longitudinal yang } \\
& \text { dihasilkan pada saat } \mathrm{S}_{2}
\end{aligned}
$$

Rumus modulus elastisitas secara teoritis dihitung dengan rumus :

$$
E_{C}=4700 \sqrt{f^{\prime} c}
$$

dimana:

$\mathrm{E}_{\mathrm{C}}=$ Modulus elastisitas beton $(\mathrm{MPa})$

$\mathrm{f}^{\prime} \mathrm{c}=$ Kuat tekan beton umur 28 hari $(\mathrm{MPa})$

Sementara untuk beton dengan nilai 1442 $\mathrm{kg} / \mathrm{m}^{3}$ sampai $2563 \mathrm{~kg} / \mathrm{m}^{3}$, dihitung dengan rumus :

$$
E_{C}=W_{C} 1,50,043 \sqrt{f^{\prime} c}
$$

dimana :

$$
\begin{aligned}
& \mathrm{E}_{\mathrm{C}}=\text { Modulus elastisitas beton }(\mathrm{MPa}) \\
& \mathrm{f}^{\prime} \mathrm{c}=\text { Kuat tekan beton umur } 28 \text { hari }(\mathrm{MPa}) \\
& \mathrm{W}_{\mathrm{C}}=\text { Berat volume beton }\left(\mathrm{kg} / \mathrm{m}^{3}\right)
\end{aligned}
$$

Tabel 3. Pengujian modulus elastisitas

\begin{tabular}{ccccc}
\hline \multirow{2}{*}{ Sampel } & \multicolumn{3}{c}{ Pengambilan Sejajar Arah Pengecoran } \\
\cline { 2 - 5 } & \multicolumn{2}{c}{$\boldsymbol{\varnothing 2 \text { inci }}$} & \multicolumn{2}{c}{$\varnothing 1$ inci } \\
\cline { 2 - 5 } & Teoritis & $\begin{array}{c}\text { Eksperim } \\
\text { ental }\end{array}$ & Teoritis & $\begin{array}{c}\text { Eksperim } \\
\text { ental }\end{array}$ \\
\hline A & $18,029.46$ & $20,505.74$ & $20,060.37$ & $22,607.79$ \\
B & $21,963.27$ & $23,141.00$ & $20,441.29$ & $24,481.08$ \\
C & $23,500.80$ & $25,150.04$ & $22,443.55$ & $27,197.69$ \\
D & $24,509.61$ & $26,382.03$ & $23,795.06$ & $28,202.56$ \\
\hline
\end{tabular}

Tabel 3 dan 4 menunjukkan hasil pengujian modulus elastisitas adalah untuk melihat nilai modulus elastisitas secara eksperimental apakah 
lebih kecil atau lebih besar dari modulus elastisitas secara teoritis.

Tabel 4. Pengujian modulus elastisitas

\begin{tabular}{ccccc}
\hline \multirow{2}{*}{ Sampel } & \multicolumn{2}{c}{ Pengambilan Tegak Lurus Arah Pengecoran } \\
\cline { 2 - 5 } & \multicolumn{2}{c}{$\boldsymbol{\varnothing} 2$ inci } & \multicolumn{2}{c}{$\boldsymbol{\varnothing ~ 1 ~ i n c i ~}$} \\
\cline { 2 - 5 } & Teoritis & $\begin{array}{c}\text { Eksperim } \\
\text { ental }\end{array}$ & Teoritis & $\begin{array}{c}\text { Eksperim } \\
\text { ental }\end{array}$ \\
\hline A & $19,242.49$ & $21,230.93$ & $19,666.21$ & $20,213.23$ \\
B & $21,631.84$ & $18,012.28$ & $21,510.18$ & $43,798.21$ \\
C & $25,001.87$ & - & $24,582.99$ & $26,395.20$ \\
D & $20,685.74$ & $31,183.00$ & $26,457.50$ & $39,214.54$ \\
\hline
\end{tabular}

\subsection{Pengujian Kuat Tekan Beton Inti}

Evaluasi kuat tekan beton inti dilakukan dengan membandingkan nilai kuat tekan antara beton inti berdiameter 2 inci dan 1 inci serta beton standar diameter $10 \mathrm{~cm}$. ASTM C42-12 mengatur dimensi penampang beton inti tidak boleh kurang dari dua kali MSA sedangkan pada BS-EN 125041:2000 menerangkan rasio MSA dalam beton terhadap diameter beton inti memiliki pengaruh signifikan terhadap kuat tekan apabila nilainya lebih besar dari 1:3. Beton inti dengan MSA yang lebih kecil memiliki nilai kuat tekan yang lebih mendekati kuat tekan beton standar.

Tabel 5 menunjukkan hasil pengujian Evaluasi Kuat Tekan Beton Inti adalah untuk melihat Faktor Korelasi beton inti terhadap beton silinder.

Tabel 5. Faktor korelasi kuat tekan beton inti

\begin{tabular}{ccccc}
\hline Sampel & \multicolumn{2}{c}{$\begin{array}{c}\text { Pengambilan Sejajar } \\
\text { Arah Pengecoran }\end{array}$} & \multicolumn{2}{c}{$\begin{array}{c}\text { Pengambilan Tegak } \\
\text { Lurus Arah } \\
\text { Pengecoran }\end{array}$} \\
& $\boldsymbol{\emptyset ~ 2 ~ i n c i ~}$ & $\boldsymbol{\emptyset ~ 1 ~ i n c i ~}$ & $\boldsymbol{\emptyset ~ 2 ~ i n c i ~}$ & $\boldsymbol{\emptyset ~ 1 ~ i n c i ~}$ \\
\hline A & 1.0364 & 1.1801 & 1.1013 & 1.3104 \\
B & 1.0205 & 1.1536 & 1.0815 & 1.1944 \\
C & 1.0364 & 1.1801 & 1.1013 & 1.3104 \\
D & 1.0205 & 1.1536 & 1.0815 & 1.1944 \\
\hline
\end{tabular}

\section{Pembahasan}

Untuk pengambilan sampel secara tegak lurus maupun sejajar arah pengecoran, menunjukkkan bahwa nilai kuat tekan pada beton inti berdiameter 1 inci lebih kecil dibandingkan dengan beton inti berdiameter 2 inci. Hal ini menunjukkan bahwa beton inti dengan diameter 1 inci memerlukan faktor koreksi yang lebih besar dibandingkan dengan beton inti berdiameter 2 inci.

Untuk pengambilan sampel secara tegak lurus maupun sejajar arah pengecoran, menunjukkkan bahwa nilai kuat tekan pada beton inti berdiameter 1 inci dan 2 inci untuk agreggat dengan MSA 20 $\mathrm{mm}$ lebih kecil dibandingkan dengan beton inti berdiameter 1 inci dan 2 inci untuk agreggat dengan MSA $10 \mathrm{~mm}$.

Untuk pengambilan sampel secara sejajar arah pengecoran, menunjukkkan bahwa nilai kuat tekan pada beton inti berdiameter 2 inci untuk mutu f'c $20 \mathrm{MPa}$ lebih besar dibandingkan dengan uji silinder standar $\varnothing 10 \mathrm{~cm}$ sedangkan untuk beton inti berdiameter 2 inci untuk mutu f'c 30 $\mathrm{MPa}$, beton inti berdiameter 1 inci untuk mutu f'c $20 \mathrm{MPa}$ dan f'c $30 \mathrm{MPa}$ lebih kecil dibandingkan dengan uji silinder standar $\varnothing 10 \mathrm{~cm}$.

Untuk pengambilan sampel secara sejajar arah pengecoran, menunjukkkan bahwa nilai kuat tekan pada beton inti berdiameter 2 inci untuk mutu f'c $20 \mathrm{MPa}$ lebih besar dibandingkan dengan uji silinder standar $\varnothing 10 \mathrm{~cm}$ sedangkan untuk beton inti berdiameter 2 inci untuk mutu f'c 30 $\mathrm{MPa}$, beton inti berdiameter 1 inci untuk mutu f'c $20 \mathrm{MPa}$ dan f'c $30 \mathrm{MPa}$ lebih kecil dibandingkan dengan uji silinder standar $\varnothing 10 \mathrm{~cm}$.

Untuk pengambilan sampel secara tegak luruh arah pengecoran, menunjukkkan bahwa nilai kuat tekan pada beton inti berdiameter 2 inci untuk mutu f'c $20 \mathrm{MPa}$ (variasi B) lebih besar dibandingkan dengan uji silinder standar $\varnothing 10 \mathrm{~cm}$ sedangkan untuk beton inti berdiameter 2 inci untuk mutu f'c $20 \mathrm{MPa}$ (variasi A), beton inti berdiameter 2 inci untuk mutu f'c $30 \mathrm{MPa}$, beton inti berdiameter 1 inci untuk mutu f'c $20 \mathrm{MPa}$ dan f'c $30 \mathrm{MPa}$ lebih kecil dibandingkan dengan uji silinder standar $\varnothing 10 \mathrm{~cm}$.

Untuk pengambilan sampel secara sejajar arah pengecoran, menunjukkkan bahwa faktor korelasi untuk beton inti 2 inci dengan MSA $20 \mathrm{~mm}$ sebesar 1,0364, untuk MSA $10 \mathrm{~mm}$ sebesar 1,0205 , sedangkan faktor korelasi untuk beton inti 1 inci dengan MSA $20 \mathrm{~mm}$ sebesar 1,1801, dan untuk MSA $10 \mathrm{~mm}$ sebesar 1,1536 untuk menyamakan dengan nilai kuat tekan beton silinder $10 \mathrm{~cm}$ untuk mutu beton antara 20 MPa hingga $30 \mathrm{MPa}$. 
Untuk pengambilan sampel secara tegak lurus arah pengecoran, menunjukkkan bahwa faktor korelasi untuk beton inti 2 inci dengan MSA 20 mm sebesar 1,1013, untuk MSA $10 \mathrm{~mm}$ sebesar 1,0815, sedangkan faktor korelasi untuk beton inti 1 inci dengan MSA $20 \mathrm{~mm}$ sebesar 1,3104, dan untuk MSA $10 \mathrm{~mm}$ sebesar 1,1944, untuk menyamakan dengan nilai kuat tekan beton silinder $10 \mathrm{~cm}$ untuk mutu beton antara 20 $\mathrm{MPa}$ hingga $30 \mathrm{MPa}$.

\section{Kesimpulan dan Saran}

Kami menyimpulkan bahwa yang memenuhi dan direkomendasikan untuk mewakili kuat tekan beton inti adalah pengambilan sejajar dengan diameter 2 inci (f'c $20 \mathrm{MPa}$ dengan MSA $20 \mathrm{~mm}$ dan MSA $10 \mathrm{~mm}$ ) dengan jumlah sampel 25 buah, sedangkan untuk yang lainnya harus ditambah jumlah sampel untuk lebih mendekati dan saran yang dapat diberikan sebagai pertimbangan dalam penelitian lebih lanjut adalah perlu dipertimbangkannya jumlah benda uji yang lebih banyak dengan mengambil variasi ukuran benda uji bentuk plat dan balok.

\section{Ucapan Terima Kasih}

Terima kasih kepada staf Laboratorium Struktur dan Bahan Departemen Teknik Sipil Universitas Hasanuddin serta para mahasiswa yang turut membantu sehingga penelitian ini dapat terlaksana dengan baik.

\section{Referensi}

[1] American Society for Testing and Material. Annual Book of ASTM Standart: Volume 04.02, Concreate and Aggregate. US and Canada. 2003.American Society for Testing and Material. ASTM Standart: C125-06a, Standard Terminology Relating to Concrete and Concrete Aggregates.

[2] American Society for Testing and Material. ASTM Standart: C42-16, Standard Test Method for Obtaining and Testing Drilled Core and Sawed Beams of Concrete.

[3] Yamamoto, Daisuke., Hamada, Hidenori., Sagawa, Yasutaka., Hiromitsu, Toshiumi. Evaluation of Compressive Strength of Concreate Using Small Diameter Core. Journal $3^{\text {rd }}$ International Conference on Sustainable Construction Materials \& Technologies SCMT3. Kyoto Research Park, Kyoto, Japan: 2013.

[4] Yamamoto, Daisuke., Hamada, Hidenori., Sagawa, Yasutaka. Variation and Its Suppression Method of Compressive Srength Obtained by Small Diameter Core Specimen. Jounal $40^{\text {th }}$ Conference on Our World in Concrete \& Structures. Singapore: 2015.

[5] SNI 03-1974-1990 tentang Metode Pengujian Kuat Tekan Beton.

[6] SNI 03-3403-1994 tentang Metode Pengujian Kuat Tekan Beton Inti Pemboran.

[7] SNI 03-2492-2002 tentang Metode Pengambilan dan Pengujian Beton Inti. 